\title{
Digital Technology Disorder: Justification and a Proposed Model of Treatment
}

\author{
Dr Andrew Kear, Sasha L. Folkes \\ Faculty of Media and Communication, Bournemouth University, UK
}

\begin{abstract}
Due to advances in technology being made at an exponential rate, organisations are attempting to compete with one another by utilising state-of-the-art technology to provide innovative products and services that encourage use. However, there is no moral code to inform sensitive technology design, a consequence of which is the emergence of so-called technology addiction. While addiction as a term is problematic, increasing evidence suggests that related-conditions present implications for the individual, for organisations and for wider society. In this research, a consideration of the potentially addictive elements of technology indicates that it can be possible to reverse engineer these systems, as it were, to promote the development of new behaviours, which can enable the individual to abstain from overuse. Utilising smartphones to deliver digital behavioural change interventions can leverage abundant data touchpoints to provide highly tailored treatment, in addition to allowing for enhanced monitoring and accuracy. To inform understanding of this contemporary phenomenon, the literature on addiction has been reviewed, along with the literature on persuasion architecture to inform an understanding of techniques that lend themselves to overuse and how these can be leveraged to promote recovery. From which, the authors have developed a proposed model to inform the practice of those operating in the domains of computer science.
\end{abstract}

Keywords-Addiction; digital; treatment; data; smartphone; behaviour; overuse; interventions

\section{INTRODUCTION}

In the $21 \mathrm{st}$ century, there has been a trend with organisations moving away from traditional channels at a rapid rate, opting to invest in their digital counterparts instead. One of the aims of these online channels is to encourage people to spend more time on them, which has been widely successful, resulting in widespread adoption of digital technology devices. Since these systems are growing in importance for both personal and organisational communications, the internet has become one of the most important marketplaces for transactions of goods and services [46], with over " 4 billion internet users recorded in 2018" [36]. With usage figures increasing at a rate of "7 per cent year-on-year" [36], there are increased opportunities for consumerism.

Resultantly, "the digital era transcends demographics": enabling marketers to "have a clearer picture of a consumer from the content they've viewed" [88]. Developers are creating highly advanced systems that are "tailored to its host's needs and reinforcement schedule", a Skinner box, as it were, that enables individuals to "interact with each other without sacrificing the integrity of their own construct" [21]. Since consumer needs are being met at an accelerating rate, spending time online can be a highly rewarding experience, "contributing to personal enjoyment for many people" [41].

However, an increasing issue is the overuse of these systems. As noted by [16], "computer systems cannot improve organizational performance if they aren't used", however, "complex social situations arise at the individual, organizational, and societal levels" as a result of overuse [14]. Though, who is to blame for overuse? Is it irrational, if immersion, specifically, engagement, is listed as being "a desirable - even essential-human response to computermediated activities?" [45]. There is thus a dichotomy between encouraged adoption of technology, and the implications that stem from overuse, with systems listed as "both a creator of certain "dark" effects and a harbinger of their antidotes" [14].

In those that exhibit "problematic levels of usage, devaluation of life itself in the real world is likely to have a major impact on the good life... requiring less effort and providing faster rewards" [41]. Influential systems can encourage "users to spend their time in the virtual realm and abandon reality", and to "value success and rewards" in alternate realities "as equal as or even higher than those in the real world, devaluating the latter" [41]. As a result of people spending excessive time online within these platforms, negative outcomes such as depressive and anxiety disorders, insomnia and so-called addiction have all been implicated with overuse [28].

These implications can encroach onto an organisational level, associated with "perceived work overload, technologyfamily conflict", compromised "organizational commitment" [79] and technostress, which accounts for "50-75 per cent of all information security breaches" in the workplace [14]. While effects such as these are becoming increasingly apparent, the only technology-related condition to be recognised in the Diagnostic and Statistical Manual of Mental Disorders (DSM-5), regarded as "the global standard for the classification of mental disorders" is Internet Gaming Disorder (IGD) [24].

Previous attempts at generating official recognition for other technology-related conditions within the DSM-5 have been unsuccessful. Resultantly, there is a lack of funding, research and resources allocated towards identifying new methods of intervention. Currently, there are treatment interventions available for several technology-related conditions. However, the literature suggests that existing treatments can be ineffective. For so-called Internet Addiction and Mobile Phone Addiction, there are detox centres and 
military-style camps, which practice abstinence from technology and seek to teach alternate behaviours.

Though effective in select cases, abundant research suggests that these types of treatment can cause more harm than good. In China, "unlicensed training camps" that seek to "wean" individuals off the internet are particularly controversial, having led to cases of casualty and even death [84]. In 2009, "15-year-old Deng Senshan" was found to be dead "just hours after he checked into an Internet bootcamp", while Pu Liang was admitted "to hospital with water in the lungs and kidney failure" just three weeks after admission [77]. Due to these instances, treatment centres came under scrutiny in 2009, and restrictions were placed on methods used, with laws set.

In 2016, however, reports surfaced of a "16-year-old" starving her mother "to death in revenge for sending her to abusive internet addiction boot camp", in which "she was beaten and abused" [58]. Since being published, the report led to several "former students" drawing attention to additional cases of "abductions, beatings, and corporal punishment" [58]. Resultantly, consent has become increasingly important in treatment interventions, with collaborative approaches becoming the norm. For example, chemical treatments can enable treatment to be delivered without the individual needing to make drastic lifestyle changes.

Typically, research indicates that anti-depressant drugs allow for both the symptoms of technology-related conditions to subside, along with co-occurring conditions to be targeted [12]. Albeit, "there has been no pharmacological agent identified to be effective" as a stand-alone treatment of technology-related conditions: "all the studies providing an indication for the application of pharmacotherapy... treatment focus first on comorbid disorders", [12]. If technology-related conditions exist in their own right, this would indicate a need for specific treatments to be devised to perhaps ensure a higher rate of recovery.

Further, while contemporary treatments are largely unimposed, there are still several barriers to the effectiveness of treatment. Universal prescription changes can act as a barrier to receiving pharmacotherapy treatments for some, due to personal income levels [37]. Costs are not confined to chemical interventions, however these being "significant barriers to providing evidence-based, behavior change interventions" [49] for healthcare professionals.

For the providers of therapeutic interventions, "financial and staffing resources" for employee training may not always be accessible "to the average community-based treatment program areas" [49]. Additionally, "the squeeze on local authorities, public health budgets" means that "teams are not getting the funding they need": resultantly, there are extended waiting lists for public treatment, causing "increasing numbers of people to self-refer for costly treatment" [72].

In addition, there are several other elements compromising the effectiveness of treatment: including geographic, political, societal and individual factors. Foremost, distance of patients to treatment centres "may be a barrier to accessing evidencebased care for many patients, especially in rural areas" [49].
Secondly, the time required for treatment interventions can be a deterrent to those with work or family commitments, since "most inpatient facilities insist patients focus completely on treatment" [37]. Finally, there is a stigma attached to addictive disorders, which can deter people from seeking treatment: "almost one-fifth of people who don't seek treatment say they fear what others would think if they went to rehab" [37].

Due to the issues listed above, it seems appropriate to make a case for new forms of treatment for so-called addictions to be identified. In the case of technology overuse, increasing prevalence rates, widespread adoption and younger device ownership make it seem more important than ever to do so. Before these can be identified, however, the authors wish to make a case for an alternate form of classification to inform treatment. While there are ideas circulating about various technology-related conditions, there is an absence of universally recognised terminology and criteria. In order to appropriately categorise such behaviours, the authors have used the following process:

1) So as not to exclude a category through semantics, 'digital technology (DT)' will refer to technology that operates via microprocessors: including computers, applications, the internet, mobile phones, as well as "devices that enable access to cyberspace, the use of digital audio/video and information communications technology (ICT)' ' [32].

2) In cases of sustained DT overuse that presents above norm negative repercussions, the term 'Digital Technology Disorder' (DTD) will be used.

3) While aspects of DTD can share elements of "natural history, phenomenology, tolerance, comorbidity, genetic contribution, neurobiological mechanisms, and response to treatment" with officially recognised addictions [23], 'disorder' has been deemed the most appropriate term. This is due to issues associated with 'addiction' (see page 3).

4) Since DTD can be compared with IGD, DTD will refer to a "compulsive-impulsive spectrum disorder" [70]. Within which, DTD will refer to cases where DTs are an end in themselves, thus refining the concept further, by excluding cases of DTs being used to enable a pre-existing addiction.

By coining the term, the authors hope to present a case for DTD to be treated as seriously as an officially recognised disorder, which could help towards changing perceptions and identifying new methods of treatment. The authors also wish to point out that, while official recognition of IGD is helpful, it does not sufficiently account for all technology-related conditions. This is due to the fundamental difference: 1) DTs have encroached on almost every aspect of life, with their usage being encouraged in areas such as work and school. Gaming remains a pastime for those who wish to peruse it unless diagnosed with IGD or in cases of employment link explanation.

Due to which, it can be harder to spot those with DTD. There would be no apparent signs, for example, that distinguish a DTD sufferer on the tube to a businessman seeking to meet targets via email. A standardised term would allow people to identify the signs and criteria and to intercept before the repugnant effects are shown. Since there are several research 
gaps regarding "how individuals understand, adopt, and learn technology outside of the formal organization" [75], the authors hope to inform sensitive DT design which promotes responsible use. In turn, the authors hope that the future of DT design strives to minimise potentially hazardous outcomes with a consideration of their power.

\section{ADDICTION}

\section{A. Issues with Addiction}

Multiple theories have been proposed to explain addiction. The literature is vast, with key themes of individual responsibility versus individual as a victim $[30,86]$, rational $[9$, 51] versus irrational; beneficial versus repugnant, as well as alternate standpoints [22]. Whilst it may seem unproductive to get caught up in semantics, these standpoints are important, since they influence and dictate treatments that are available. As noted by [10], ambiguity "about the meaning of the term "addiction" is not confined to "academic debates... these differing perceptions "matter" in many ways",

Formerly, perceptions "that are held by scientists and policy makers are likely to influence their policy decisions", including allocation of resources "for the treatment and prevention of addictive behaviors" [10]. Moreover, attitudes towards addictive behaviours can impinge upon an individual's understanding of the consequential outcomes and in turn, affect levels of engagement. This may be particularly problematic for vulnerable groups in the population, such as "adolescents, who are at the ages during which many of these behaviors are commonly initiated"' [10].

The crucial element here is that prescribed treatment seems to depend, largely, on the perspective. For example, in Asia, the concept of Internet Addiction (IA) is well established, with perceptions of it being a threat to public health. There has been abundant research into prevalence rates, criteria, symptoms, risks and treatments. In 2008 alone, figures estimated that 210,000 children in South Korea (6-18 years old) were undergoing treatment for IA, a number which is predicted to have significantly increased [15]. As "the average South Korean high school student spends about 23 hours each week gaming, another 1.2 million are believed to be at risk for addiction and to require basic counselling" [15].

Consequently, the South Korean government have "trained 1,043 counsellors in the treatment of Internet addiction and enlisted over 190 hospitals and treatment centres', in addition to setting up "preventative measures" in education [15]. Similarly, in China, it was predicted that " $13.7 \%$ of Chinese adolescent Internet users meet Internet addiction diagnostic criteria" in 2008, which equates to "about 10 million teenagers" [15]. Thus, the government and legal system in Asia have sought to reduce the interactions with computers among its teenagers, by stigmatising things such as "more than 3 hours of daily game use"' [8].

In other parts of the world, such as America, statistics on prevalence rates of similar conditions are lacking, perhaps as a result of differences in public and private consumption. In Asia, internet cafes act as a means of observation for DTD symptoms, however, "in the United States games and virtual sex are accessed from the home", [8]. Further, "attempts to measure the phenomenon are clouded by shame, denial, and minimization" [8]. As a result, there are fewer treatments available in the US; hence, it seems appropriate to deduce that the different perspectives can be integral to the different treatments prescribed.

Due to differing standpoints, addiction "has been criticized both within and outside the mental health disciplines on a number of grounds" [22]. Addiction is largely subjective: in order to define addiction, "we must select some aspects to include and empathize, and others to exclude" [6]. Prerequisites such as "scientific, guild, societal, and political considerations" both influence and dictate definitions [6], thus addiction is "historically and culturally specific" [6]. Resultantly, contemporary definitions of addiction can be discordant with traditional theories of anthropology, behaviourism and cognitive processing $[22,48]$.

\section{B. Broadening Scope of Addiction}

Prior to the Theory of Rational Addiction [3], "most of the literature in this area until the mid-1980s modelled addiction as habit formation', specifically, irrational ones [27]. In recent more years, however, the notion that basic activities "can be properly described as addictive" has surfaced [27]. This is because "people get addicted to not only alcohol, cocaine and cigarettes but also to work, eating, music, television, their standard of living, other people" [3], as they conform to "the two conditions required for addiction: reinforcement, and tolerance", [27].

As noted by [30]: "what is coming up fast as being the central core issue ... is continued engagement in selfdestructive behaviour despite adverse consequences". Ideas about the existence of behavioural addictions have surfaced, including "what some are calling positive addictions (exercise, meditation)" [7]. Resultantly, addiction is being attributed to numerous behaviours, resulting in worries that "if what is labelled addiction becomes too broad, the word addiction will become devoid of meaning", [7].

While an increased scope of addictive behaviours could "be justified if common features exist across a similar set of behaviours", that allow us to better "understand addictive problems and expand society's capacity to intervene', there are notable concerns [7]. As illustrated by Heller (2008 cited by) [61]: "if every gratified craving from heroin to designer handbags is a symptom of "addiction," then the term explains everything and nothing". Hence, the term "addiction" should be used with caution when referring to behaviours that are not listed as being official within the DSM-5, while a mainstream understanding of the difference between "addictions" and "disorders" would perhaps enable more consistent categorisation.

\section{THEORIES OF ADDICTION CREATION}

The following section seeks to identify patterns within how addiction is formed. Primarily, theories of addiction creation will be explored, since "the best way to understand and, ultimately, to change addictions is to understand why and how they began", [7]. 


\section{A. Associative Learning}

Though Pavlovian conditioning (Pavlov 1927) and instrumental conditioning (Skinner 1938) are both included within the realm of associative learning, these substrates have crucial differences [52]. Formerly, they differ in terms of experimental grounding. In Pavlov's (1927) original experiment, "the existence of the unconditioned response" was made apparent by "presenting a dog with a bowl of food and the measuring its salivary secretions"; leading to the discovery that "any object or event which the dogs learnt to associate with food (such as the lab assistant) would trigger the same response"' [52].

Therefore, Pavlovian conditioning "involves automatic or reflexive responses" to sign-posted stimuli, whereby "conditioned stimuli (CSs) elicit conditioned responses (CRs)", [4]. For example, "anticipatory responses, behavioural habits or even conditioned motivations and emotions" that are "appropriate to the unconditioned reward stimulus (UCS)" [4]. By comparison, instrumental conditioning considers voluntary behaviour. In Skinner's (1938) original experiment, in which rats were observed in The Skinner Box, "actions that are instrumental in gaining access to rewards, such as lever pressing for food" were found to "be controlled by two distinct associative processes" [87].

In the onset, a behaviour is "goal-directed and mediated by the encoding of an association between the action and its specific consequences or outcome", thus, "instrumental performance" can "be sensitive both to non-contingent reward delivery" and to "changes in outcome value" [87]. Over time, however, there is a profound shift. This is due to "control over performance" being "found to shift to a stimulus-response process", whereby 'actions become stimulus-bound or habitual", resultantly, actions become de-sensitised "to changes in either the instrumental contingency or reward value", [87].

Types of associative learning also differ in terms of the reward prediction process. Pavlovian conditioning refers to "stimulus-stimulus associations and predictive reward expectation", or "stimulus-response associations and actoutcome representations" [4]. Instrumental conditioning entails 'response-contingent reinforcement", whereby "specific instrumental responses are strengthened by responsecontingent reinforcement" [4]. Despite these differences, both forms of associative learning are analogous in their application to teaching new behaviours. By understanding both substrates in the context of addiction, it can be possible to deduce several aspects.

Formerly, potential addictions can be conditioned, thus conditioning techniques could be utilised, in turn, to reverse the process and promote new behaviours in the proposed model. For example, having identified in Pavlovian conditioning that sign-posting can elicit an involuntary response, perhaps signposting can be used to prevent the formation of potential addictions, by intercepting behaviour at the point of reward expectation. As instrumental conditioning outlines how behaviour is dictated in the onset by associations with actions and the outcome assisted perhaps through educative intervention at an early stage to create new associations, will provide a greater chance of recovery.

Further, instrumental conditioning bears similarities with O-PT, for its illustration of reward de-sensitisation within addiction formation, and TMRA, with its "diminished euphoric capital" [73]. This could indicate that disorder subjects can be characterised by above normal levels of reward desensitisation, hence, this will be examined further in the 'Mind' section. While associative learning has allowed for findings such as these to be extrapolated, there are limitations to their application. For example, instrumental conditioning deals only "with expressible behaviours" [64]. Therefore, there are gaps in understanding inner processes that may play a profound role in addiction development. To uncover these, the next section will explore the mind.

\section{Mind AND NEUROPROCESSING}

Despite differences in reward processing, "neural substrates" for both forms of associative learning "are distributed relatively widely across both subcortical and cortical brain structures" [4]. Though psychological components are listed individually, "categories of motivation, learning and emotion or affect constantly interact in reward", with N-S-RDs being "particularly sensitive to different processes" [4]. This indicates that addictions and disorders entail a combination of intertwined processes that require "brain manipulations" to "dissociate many of these processes to reveal their psychological and neural separation" [4].

In particular "manipulations of mesolimbic dopamine systems" have been found to alter "reward 'wanting' without changing reward "liking", [5]. Therefore, "neural manipulations could influence rewarded behavior because they alter any one of many forms of learning', the outcome of which will be determined by "precisely which form is altered" [4].

It can be useful to gain an understanding of these systems, to see if it can be possible to utilise this knowledge to promote behavioural shifts within the proposed model. Since this paper seeks to treat an impulsive-compulsive disorder, pathophysiology of officially listed addictions (S-RADs) and officially listed disorders (N-S-RDs) will be drawn upon, so that appropriate conclusions can be made. There are several key similarities to cover, starting with neurocircuitry.

\section{A. Neuroadaptations}

A key element of S-RADs is neuroadaptations, which entail a tri-part mental process, including "preoccupation / anticipation, binge intoxication, and withdrawal/negative affect" [43]. This evidence of neuroplasticity has been said to contribute to the transition from a "disorder, that moves from impulsivity to compulsivity", to an addiction [43]. If N-S-RDs can be proven to exhibit similar neuroplasticity, it would indicate a need for time-effective treatment interventions, to intercept behaviour before it is able to develop into an addiction.

Increasing research "suggests that non-drug addictions may lead to neuroadaptations similar to those reported with longterm drug use" [56]. This indicates similar neurocircuitry 
regarding "reward processing and decision-making" in both S-RADs and N-S-RDs [86], which could infer that there are certain preconditions that each of these conditions entail. To identify aspects of these, underlying biological mechanisms will be examined.

\section{B. Underlying Biological Mechanisms}

In N-S-RDs, similar locations to those for S RADs, for reward processing have been indicated [86]. Thus, urges in SRADs and N-S-RDs, particularly of the "urge-driven" sort, "may reflect a unitary process" due to similarities in core biological mechanisms [23]. This indicates a need for treatments to integrate aspects of cognition and chemical manipulations to ensure disassociations can be made.

The particular reward pathway (the mesolimbic pathway) [86] indicates that deficiencies in the onset can lead to the development of both conditions, or promote sustained engagement, despite repugnant consequences. If subjects are attempting to self-medicate, this may lend itself towards identifying ways of shifting dependency from maladaptive behaviours to desired behaviours. If promoted behaviours are able to provide rewards that are as effective as existing ones, thus accounting for pre-existing deficits, it could allow an individual to abstain from maladaptive ones. To identify ways of achieving this, specific components of rewards, including implicated neurotransmitters will be examined further.

\section{Neurotransmitters}

The serotonergic and dopaminergic neurotransmitters associated with S-RADs [23] have been found to be implicated in N-S-RDs [86], with the regulation of "emotions, motivation, decision making, behavioral control" [86] and "inhibition of behavior" [23]; an impairment of serotonin has frequently been linked to S-RADs. Regarding N-S-RDs, impulsivity has been linked to "dysregulated serotonin functioning", due to "hormonal response after administration of serotonergic drugs" [23].

This indicates that chemical treatments of the serotonergic sort may allow for regulated control within disorder subjects, and therefore, act as a means of achieving behavioural alterations due to enhanced decision-making. While this is promising as a method of treating those with disorders, chemical interventions are costly and therefore may be a barrier to treatment for some. Albeit, the literature suggests that dopaminergic manipulations are possible without medicinal interventions.

Since dopamine is "involved with learning, motivation, and the salience of stimuli, including rewards" [23]; dopamine deficiency has been hypothesised as one of the underlying causes of S-RADs [23] and N-S-RDs [30]. Therefore, "alterations in dopaminergic pathways" are thought to drive subjects with S-RADs and N-S-RDs to repeatedly seek rewards, "that trigger the release of dopamine and produce feelings of pleasure" [23].

Dopaminergic neurons are activated when rewards are received and are heightened through elements of surprise. When rewards become expected, the dopaminergic neurons become emaciated, as they "respond physically to rewards in a manner compatible with the coding of prediction errors" [83].
The principle of instrumental conditioning can lend itself to interpreting this, whereby "learning is blocked when the stimulus is paired with a fully predicted reward" [83].

Resultantly, "the responses of dopamine neurons to conditioned stimuli" can be said to be "governed differentially by the occurrence of reward prediction errors rather than stimulus-reward associations alone"' [83]. In addition [83] suggests that when an error is present at the time of the reward, there is enhanced "behavioural and neuronal learning", a process both exacerbated and encouraged by dopaminergic neurons. Knowledge of dopaminergic neurons will be carried forward and interpreted within this paper, due to its potential to enhance treatment.

\section{CONCLUSIONS}

To ensure that this lends itself towards developing a model of treatment, several elements have been identified. Having examined the literature on addiction formation and how habits are formed, it seems that the preconditions of potential disorders can include: dopamine deficits, which motivate subjects to engage in certain behaviours over others; above norm levels of reward de-sensitisation which cause repeated reward seeking; above norm need for variable rewards or stimulation to overcome these.

In addition to the aforementioned preconditions, the tools are as follows: unpredictable rewards can lead to habitformation, which increases motivation to engage in behaviours that enable dopamine deficits to be fulfilled; prediction errors enable enhanced learning, due to dopamine release; behaviours are mediated by associations in the onset of instrumental conditioning. Therefore, any model that seeks to treat disorders should include aspects of "neural manipulations to separate the processes" that are implicated with disorders [4], which may compromise the subject's abilities to make decisions.

For example, with dopaminergic manipulations or signposting to elicit a conditioned response to new behaviours and to form associations that replace existing reward gratification for maladaptive behaviours. In addition, dopaminergic manipulations should be utilised throughout treatment, to prevent relapse by accounting for potential pre-existing dopamine deficits. Further, models should seek to provide rewards of sufficient variance to motivate subjects to participate in sustained treatment over engaging in maladaptive behaviours. Additionally, prediction errors should be utilised to promote enhanced learning, by overcoming the reward desensitisation process that contributes to disorders and to ensure that treatments incur maximum effect.

In addition, treatment interventions must be prompt and accessible, to intercept subjects at key points of habit formation, before disorders develop into potential addiction. Finally, educative intervention should be used to change associations that drive behaviour, with guidance on how to develop new coping mechanisms, thus transforming cases of approach-avoidance conflict into cases of approach-approach. To summarise, any model that seeks to treat disorders should cover aspects of motivation, learning and emotion to guide behavioural alterations and separate entwined processes. Relevant findings could lend themselves towards identifying 
ways of ascertaining how the mind is processing things whilst subjects are engaged in technology.

Thus, if we want to alter this within treatment, we might want to employ techniques that highlight which areas of the brain are activated and which chemicals are released, post disorder, to see if treatment has been successful. However, there is still a gap in relation to DTD, and how these techniques may lend themselves to treating that. Despite the conclusions drawn, it is not possible to conclude which aspects of technology lend themselves to irrational habit formation. Therefore, section 2 will seek to explore technology techniques and how these contribute to potential disorders. In turn, this will inform the development of a proposed model.

\section{PERSUASION ARCHITECTURE}

This section aims to explore technology techniques and how these may lead to addiction. From which, it can be possible to identify how techniques can be leveraged to promote recovery. Primarily, if we can understand systems, we can attempt to understand how an individual might overuse these. Despite rapid advancements in technology being made, "one of the continuing issues of DTs is identifying factors that cause people to accept and make use of systems developed and implemented by others" [39]. Since [38] posited that the solution to effective user interface (UI) design is a "process of manager-analyst interaction in the explication" of assigned models. Though several academics have sought to identify what constitutes acceptance of electronic UI design.

\section{A. User Interface Acceptance}

The author in [71] "proposed that a distinction had to be made between technical and organizational validity", to gain an understanding as to "why systems that met all technical performance standards still were not universally used or understood" [39]. Davis (1985) devised the technology acceptance model (TAM) two years later [15], depicting "the effect of system characteristics on user acceptance of computer-based information systems" [16]. Within TAM, stages can be broken down into design, cognitive, affective and behavioural, with arrows depicting casual relationships.

TAM consists of "two primary predictors - perceived ease of use (EU) and perceived usefulness (U) and the dependent variable behavioural intention (BI)" [39]; assuming that a "potential user's overall attitude toward using a given system" is "a major determinant of whether or not he actually uses it" [11]. Though highly regarded due to its refined style, TAM is not without criticism: "TAM relationships are not borne out in all studies", due to a "wide variation in the predicted effects in various studies with different types of users and systems" [39].

Consequently, TAM has been adapted by reference [81] to create TAM2, with added elements such as 'Social Influence', which entails "three interrelated social forces impinging on an individual facing the opportunity to adopt or reject a new system'. TAM2 presents several implications. For example, past experience also plays a role in leading to perceived usefulness, intention to use, and consequential use. Hence, if the systems can alter these experiences in the onset, this may be a way of promoting behavioural shifts in treatment.

Further, since voluntariness is listed, it is important for the proposed model to be consensual. In addition, since subjective norm is listed, classifying overuse as DTD could help in shifting perceptions, by making users aware of the implications that stem from overuse. Finally, TAM2 indicates that adequate returns to satisfy stakeholders can still be achieved in cases of technology design that does not seek to encourage overuse. Instead, there is the potential for new business models to be developed, which focus on the ability of the device to act as a mediator of maladaptive behaviour.

This could be used as a key selling point for brands to enhance their image, from which, relevant returns could fuel the development of strategies that ensure that issues that stem from overuse do not affect future society. While TAM2 has been useful in enabling the above to be extracted, it does not detail elements of individual disengagement. As noted by reference [55]: "one area of future research is examining... the specific notion of disengagement... when, if ever, does intense engagement cross the line into addiction?" Hence, the role of engagement will be examined in more detail in the next section, by identifying how much technology leads to behavioural patterns that are irrational.

\section{B. Role of Engagement}

Several scholars have listed engagement as a requisite of usability [45]. Listed as the "physical, cognitive, and affective components of user experiences"; engagement entails "media presentation, perceived user control, choice, challenge, feedback, and variety" [55]. In their Proposed Model of Engagement, [55] suggest that engagement and disengagement can occur within the same interaction period, inferring that ' 'engagement itself operates on a continuum...it may be poor, average, or high".

We can assume, therefore, that to be inflicted with DTD, one must be ranked high and frequent on the engagement scale. Though, high engagement over short periods of time, perhaps when searching for a particular thing online, may not entail DTD: it must be those that score low in disengagement and high on engagement. The Proposed Model of Engagement [55] can also lend itself towards identifying the techniques that encourage excessive use and what techniques reduce that. These will be explored in more detail in the next section.

\section{Elements that Promote Engagement}

Having previously covered motivation, interest and goals, these will not be examined further. Other elements of engagement, however, should lend themselves towards informing the proposed model, which seeks to reduce overuse. To ensure theory can be translated into practice, proposed elements of engagement, taken from The Proposed Model of Engagement [55] have been compared with the specific techniques that are utilised in DTs to achieve these in Table I. 
TABLE I. TECHNIQUES USED TO INCREASE ENGAGEMENT

\begin{tabular}{|c|c|}
\hline $\begin{array}{l}\text { Engagement } \\
\text { Attributes }\end{array}$ & Techniques Used in DTs to Achieve These \\
\hline $\begin{array}{l}\text { Aesthetic/ } \\
\text { sensory } \\
\text { appeal }\end{array}$ & $\begin{array}{l}\text { Sounds and vibrations that accompany notifications } \\
\text { have been found to "align an external trigger (the ping) } \\
\text { with an internal trigger (a feeling of boredom, } \\
\text { uncertainty, insecurity)", thus are utilised within } \\
\text { systems and applications to promote usage [42]. } \\
\text { Similarly, rich colours can be integrated into systems to } \\
\text { increase aesthetic appeal [40]. }\end{array}$ \\
\hline $\begin{array}{l}\text { Novelty and } \\
\text { attention }\end{array}$ & $\begin{array}{l}\text { Elements such as "variable rewards" are provided to the } \\
\text { user, that "are only sometimes distributed", hence, "the } \\
\text { user comes to anticipate the slight rush of the fleeting } \\
\text { reward"' [17]. Since rewards are unreliable, "the twitchy } \\
\text { behavior is triggered",, whereby the user feels } \\
\text { compelled "to keep checking for messages, likes, and } \\
\text { status updates"' [17]. } \\
\text { Techniques such as "app notifications, autoplay, likes } \\
\text { and messages that self-destruct" have been } \\
\text { "scientifically proven to compel" users to engage in } \\
\text { DTs: by making users feel as if they are "missing } \\
\text { something really important", systems can motivate } \\
\text { users "to watch/check in/respond right now" [42]. }\end{array}$ \\
\hline Control & $\begin{array}{l}\text { Systems can create the illusion of control, to attract } \\
\text { users that lack perceived control in real life. Reference } \\
\text { [80] note that the common aspects that contribute to this } \\
\text { perceived lack of control are: "need for approval ( } 75 \% \\
\text { for addicts vs. } 36 \% \text { for regular users)', "fear of } \\
\text { rejection ( } 64 \% \text { vs. } 36 \%) \text { ", "loneliness ( } 64 \% \text { vs. } 38 \%) \text { ", } \\
\text { and "anxiety ( } 64 \% \text { vs. } 36 \%) \text { ". By enabling the user to } \\
\text { progress through stages, work towards rewards, or attain } \\
\text { social validation, these illusions of control can be } \\
\text { capitalised upon to drive engagement. }\end{array}$ \\
\hline Interactivity & $\begin{array}{l}\text { Unpredictability can encourage interaction with devices, } \\
\text { due to a human tendency to avoid boredom. In } 2014 \text {, an } \\
\text { experiment revealed that "people actually preferred to } \\
\text { shock themselves than sit alone with their thoughts for } \\
20 \text { minutes", indicating that "many of us would prefer } \\
\text { chaos over predictability in our daily lives", [25]. By } \\
\text { "reinforcing this notion", social media provides a } \\
\text { fluctuating "feedback loop that becomes more arresting } \\
\text { the more we use it" [25]. }\end{array}$ \\
\hline Challenge & $\begin{array}{l}\text { Gamification refers to injecting "gameplay elements in } \\
\text { non-gaming settings" to "enhance user engagement } \\
\text { with a product or service"' [76]. Integrating elements } \\
\text { such as "leaderboards and badges into an existing } \\
\text { system" can enable developers to "tap" into "users' } \\
\text { intrinsic motivations", in doing so, ignite a desire within } \\
\text { the user to participate in the challenge [76]. }\end{array}$ \\
\hline Feedback & $\begin{array}{l}\text { Algorithms can be utilised "to determine the moment", } \\
\text { the user "might otherwise walk away", at which point, } \\
\text { certain rewards can be delivered, such as "small wins", } \\
\text { to keep the person playing"' [51]. }\end{array}$ \\
\hline Postive affect & $\begin{array}{l}\text { Systems can promote "short-term dopamine-driven } \\
\text { feedback loops" with likes, shares or interest in online } \\
\text { profiles [17]. These so-called "Vanity Metrics"' [25] } \\
\text { capitalise upon the "goal-obsessed culture"' that } \\
\text { permeates within contemporary society, leading to users } \\
\text { feeling obliged to chase further goals that are } \\
\text { encouraged within social media and applications [51]. }\end{array}$ \\
\hline
\end{tabular}

\section{Elements that Promote Disengagement}

Having identified that those with DTDs score high on engagement and low on disengagement, frequently and for extended periods of time; external factors will not be examined in more detail. Instead of considering aspects such as system malfunctions or physical interruptions, Table II outlines specific ways of utilising disengagement aspects within the proposed model. In turn, this should lend itself towards identifying if there can be electronic user interfaces (UIs) that help with DTDs.

TABLE II. DISENGAGEMENT ATTRIBUTES TO INCLUDE IN THE MODEL

\begin{tabular}{|c|c|}
\hline $\begin{array}{c}\text { Disengagement } \\
\text { Attributes }\end{array}$ & Aspects to Include in Model \\
\hline Percieved time & $\begin{array}{l}\text { Making the user aware of the time spent on their } \\
\text { device, with frequent usage reports and/or } \\
\text { dashboards that highlight cases of above normal } \\
\text { usage. Since DTD individuals can be influenced by } \\
\text { the behaviours of others, perhaps reports could } \\
\text { detail levels of progress achieved by others } \\
\text { (ensuring anonymity, however), which they could } \\
\text { aspire to reach. } \\
\text { Instilling time limits on certain aspects of DTs (that } \\
\text { have been identified or consented to by the user as } \\
\text { means of achieving their goals). }\end{array}$ \\
\hline Negative affect & $\begin{array}{l}\text { Shifting colours to grayscale [40], or by reducing } \\
\text { sounds and vibrations to reduce aesthetic and } \\
\text { sensory appeal. }\end{array}$ \\
\hline Disruptions & $\begin{array}{l}\text { Intercepting behaviours that indicate deviations } \\
\text { from goals, for self-reflection. Since research } \\
\text { indicates "that successfully rewiring one's habits } \\
\text { hinges in large part on self-reflection", it is } \\
\text { important that these are provided "in the middle of } \\
\text { the habit", to enable users to "stop and confront" } \\
\text { their behaviour, and "consider how" they "might } \\
\text { change it" [21]. } \\
\text { Utilising notification tiers, decided collaboratively. } \\
\text { For example, there could be levels that dictate } \\
\text { which notifications are allowed during downtime, to } \\
\text { disrupt the user's expectation to receive continuous } \\
\text { stimulation. }\end{array}$ \\
\hline Positive affect & $\begin{array}{l}\text { Utilising an AI nurse, to offer methods of coping } \\
\text { better in the real world, such as mindfulness, thus } \\
\text { reducing dependency on device. } \\
\text { Providing positive rewards that entail offline } \\
\text { activities, thus utilising gamification to encourage } \\
\text { the user "become actively interested in attaining } \\
\text { goals" [76]. } \\
\text { Sending "auto-responses during downtime", to } \\
\text { avoid the user worrying about missing anything } \\
\text { important and to generate a sense of community } \\
\text { support [63]. }\end{array}$ \\
\hline
\end{tabular}

\section{E. Alternate Methods of Promoting Disengagement}

Since the proposed model seeks to disrupt users flow, findings from neuroscience regarding implicit memory retrieval can lend themselves towards identifying how to activate alternate brain regions. In "An Electrophysiological Signature of Unconscious Recognition Memory", an experiment [82] found that "people can accurately discriminate repeat stimuli from new stimuli without necessarily knowing it'. In the experiment, participants were shown a collection of "kaleidoscopic images" and asked "to devote their full attention to half of the images, but were distracted by a number task while viewing the remaining half"' [47].

Shortly after, participants were asked to "distinguish an image they had previously seen from a new, but very similar picture": surprisingly, the participants "guessed" correctly more often than they "remembered' correctly" [47]. Thus, 
there is evidence that "implicit memory... can occur without the awareness of memory retrieval" [81]. If kaleidoscopic images can promote regions in the brain that an individual is "unconsciously" aware of, this may be a means of the proposed model impacting on the normal flow of activity in the minds of DTD subjects. In turn, this could lead to distractionconflict. For example, if a series of images were shown throughout phases of treatment, repeated exposure could promote brain regions that are atypical to those activated when using DTs.

\section{F. Choice of Platform for Treatment}

The above seems promising for enabling UIs to help treat DTDs. Widespread adoption of smartphones indicates that smartphone-based treatments can "transcend geographic boundaries", by enabling "on-demand access to therapeutic support outside of formal care settings anytime and anywhere", [50]. In addition, smartphone-based treatments could allow for "linkages to services in one's community" through GPS [50] to be made. Further, smartphones can reduce costs of treatment. While the "initial development" of smartphonebased "programs can be costly, the cost of hosting and maintaining access to them thereafter" is usually confined "to costs associated with bandwidth needs for deployment and limited technical support', [50].

\section{G. Digital Phenotyping}

Since "early recognition of sub-syndromal mood and anxiety symptoms" is paramount in lessening "the pernicious impact of chronic psychological distress and loss of function", [62], there is a need for timely monitoring of disorder subjects' behaviour. Utilising multifarious digital touchpoints on smartphones can allow for 'behavioural indicators' to be collected and interpreted promptly [62]. This is due to digital phenotyping (DP), which involves "moment-by-moment quantification of the individual-level human phenotype in situ using data from personal digital devices" [78]. From which, representations of "a person's real-time psychological state and overall profile based on their interactions with their smartphone', [13] can be generated.

This is because "digital fingerprints" are thought to "reflect the lived experiences of people in their natural environments" [57], thus giving DP the potential to reveal key behavioural insights on a granular level. Utilising "digital trace data... collected from sensors embedded on mobile devices" [62], DP could gather both active and passive patient data. Active refers to elements that require participation from the user, such as online survey responses or recorded speech samples [78]. For example, speech recordings "could be used to detect vocal markers of mood" [57]. By analysing "lexical content", "prosody, voice quality" and the "overall tone of voice", these "vocal cues can provide valuable insights into physical and mental states", [62].

Passive data includes aspects that do not require user participation, such as sleep monitoring, or data acquired from geo-spatial trajectories like the Global Positioning System (GPS). In [62] note that passive data "can enable the identification and tracking" of phenomena such as "mood, fatigue, social connectedness" and "physical isolation". By monitoring, for example, a fluctuation in sleep levels and dramatic decreases in movement via GPS, DP "could indicate depression symptoms" [13]. Further, anonymous "call logs" can allow those who fall below the average call reciprocity rate to be identified [62], in turn, allow for the identification of those with an avoidance tendency. Passive data "might also be less susceptible to the complexities introduced by potential linguistic and cultural barriers than more traditional surveys" [57].

Albeit, when passive and active forms are combined, DP could enable the proposed model to not only identify maladaptive behaviours but to promote wellbeing. For example, by providing real-time feedback to the user informing them of their usage patterns, or by highlighting "indices associated with preferred mental states and enhanced behavioural outcomes" [57]. By combining passive and active data with existing medical records, DP can allow for continuous monitoring of behaviour, for inferences in patterns to be made and to ensure that treatment is tailored to individual needs. In addition, it could be possible to "develop precise and temporally dynamic disease phenotypes and markers to diagnose and treat psychiatric and other illnesses" [57].

Thus, DP could enable the model to provide feedback and interruptions at the point of over-engagement, as well as allowing for "the early detection of various conditions" [13]. Since DP does not require "specialized research devices" like other therapeutic interventions such as ecological momentary assessment (EMA), "it is substantially more scalable than traditional implementations" that require "personal digital assistants" [57]. Furthermore, techniques used within treatment can remain up-to-date, by being connected to a cloud-based system; while advances in machine learning can be utilised, such as digital assistants, to provide phone coaching.

\section{H. Neuro-Linguistic Programming and Textual Entailment}

Since the proposed model seeks to teach new behaviours, existing techniques from the field of education can be employed. Neuro-Linguistic Programming (N-LP) is used to understand individual differences in thought-processing, methods of communication and "how this communication creates different patterns of behaviour" [33]. N-LP posits "that each individual tends to have a preferred sensory representational system" that is used to "internally code" experiences [74].

By allowing subjects to "adopt an observer position and to interpret their circumstances from a new perspective', N-LP seeks to "replace dysfunctional thoughts" within subjects that experience "psychological hardship" [69]. N-LP operates under several principles, including the notion that "meaning must match the response" [33]. According to which, both teaching and learning must be a fluid process to ensure that the desired outcome is met by the subject's behaviour [33]. Fluidity entails variances in "the teaching pattern" employed by the instructor up to the point of generating "the desired response", in addition to the style of learning used by the learner [33].

Since the proposed model uses DP to attain a stream of real-time active and passive data to provide feedback and alterations in treatment, N-LP is consistent with the authors 
understanding of teaching new behaviours. Hence, N-LP will be examined further, to identify techniques that lend themselves towards informing the proposed model. Metamodel questions (M-MQs), for example, can be used to uncover "language patterns that are believed to reflect fundamental cognitive processes" [68]. M-MQs are built on the notion that humans recall events through a "process of generalizing, deleting and distorting information", which presents implications such as a compromised ability to generate unbiased representations of events [34].

Overtly biased representations of events can impact "the person's future thinking, core values and health and wellbeing" [34]. By integrating M-MQs into the proposed model, it could be possible to uncover underlying linguistic processes in subjects, resultantly, to tailor treatment by targeting individual mental models. Advances in technology such as Natural Language Processing (NLP) in Artificial Intelligence (AI) can enable theory to be translated into practice within the proposed model. For instance, by utilising Textual Entailment (TE) models. As noted by reference [19], "TE models take a pair of sentences and predict whether the facts in the first necessarily imply the facts in the second".

If the proposed model featured aspects of TE models, it could be possible to uncover not just responses to M-MQs, but an individual's overall response to treatment. Further, periods of relapse could be sign-posted, from which, interceptions can be made in real-time. Forms of TE models can be implemented using a virtual agent, an AI nurse, as it were, to guide subjects through treatment. This will be explored in more detail in the next section, which covers models of computational persuasion, theory and application to the proposed model.

\section{Computational Persuasion}

As defined in [18], "captology describes the shaded area where computing technology and persuasion overlap'. Since DTs have been found to be detrimental to health in the cases of DTD subjects, an understanding of captology is important in informing the proposed model. Integrating aspects of captology can enable "systems to help people make positive changes to their behaviour, particularly in healthcare and healthy lifestyles" [31]. In particular, by featuring an automated persuasion system (APS) within the model, which "is a system that can engage in a dialogue with a user, i.e. a persuadee, in order to persuade that persuadee to do (or not do) some action or to believe (or not believe) something" [31]. From which, it is conceivable that the model could guide the subjects towards enhanced mental health.

Argument-centric approaches within APS are highlighted [9] to promote behavioural change: "an argument-based approach could be highly beneficial, particularly when someone is lacking some key information, and/or entertaining misconceptions about a topic'. From which, "the system may be able to change the user's mind about belief in some key arguments", resultantly, "persuade the user to believe and follow up the persuasion goal" [9]. While the explicit intent is an important consideration, the implicit are also key considerations, since "technology will always be used within a context involving users' own intentions" [44].
Factors such as "perceived social norms", "social pressure", "emotional issues" and "agenda" in addition to "perception of an issue", "opportunities to change behaviour", "attitude to persuader" and "attitude to information" [31] all affect the effectiveness of persuasion. In [35] note that there is a "lack of a model which can provide a unified framework for different persuasion strategies... specifically, persuasion is not adaptable to the individuals' personal states in different situations",

Thus, [35] propose "a computational model called Model for Adaptive Persuasion (MAP) for virtual agents', which entails "a semi-connected network model which enables an agent to adapt its persuasion strategies through feedback'. Implementations of the MAP in the form of a virtual nurse were found to be successful in changing the persuades "attitudes and behaviors intentionally, interpret individual differences between users and adapt to user's behavior for effective persuasion" [35]. Similar to which, the model could feature a MAP-based nurse that utilises data obtained consistently throughout treatment via DP to tailor treatment and make personalised recommendations based on user's habits and attitudes.

\section{CONCLUSIONS}

Having considered the above, it seems appropriate to deduce the following. The stimuli in DTs that can be said to contribute to DTDs include: sounds, rich colours and vibrations (sensory appeal); variable rewards, unpredictability, notifications (novelty and attention); stages to progress through, rewards, social validation (perceived control); fluctuating feedback loops (interactivity); gamification, leaderboards, badges (challenge); wins delivered at point of indicated disengagement (feedback); "short-term dopaminedriven feedback loops" [17], "Vanity Metrics" [25] and goals (positive affect).

These will inform the proposed model, as specific aspects to target. The stimuli also indicate the following conditions of DTD subjects: above norm need for sensory stimulation; reward de-sensitisation, low attention span; lack of perceived control in real life; above norm feelings of loneliness and anxiety; above norm need for intellectual stimulation; above norm need for feedback; pre-existing deficits of dopamine; above norm need for social validation and guidance.

\section{ANALYSIS OF FINDINGS AND PROPOSED MODEL}

Methods of how we learn and become addicted have been explored, along with similarities having been found. In addition, models of effective UI design have been identified that comprehensively outline how systems should be designed that capitalise on human user interaction. Based on findings from sections 1 and 2, it seems appropriate to deduce that the sophistication of technological devices capitalises upon the fragilities of how people learn, to the detriment of human society. Given that DTs are becoming "more sophisticated and their application in different contexts and environments expands" [1], an awareness of the power that technology holds over users is increasingly important. 
The literature on addiction and persuasion architecture suggests that the problem of DTD can be derived by computer science techniques manipulating the mind. Due to which, an argument can be made that cognitive solutions are superior to their chemical counterparts. If the systems lend themselves to DTD development, utilising these to promote digital behavioural change interventions can ensure that the issue is targeted at the source, rather than being masked. This may mean that cases of relapse are minimised, in addition to intercepting DTD before it is able to progress into an addiction. Resultantly, there could be a greater chance of recovery, along with minimised negative repercussions.

By "enabling users to face up to their unwanted behaviours as they perform them" [21], cognitive solutions, such as DBCIs, can allow users to achieve a relationship with DTs that is compatible with their desired self. Since integrating aspects of sensitive design into systems can ensure that interactions with DTs are purely productive and cause minimal harm [63], DT-based treatments have the considerable potential of "improving outcomes, reducing costs, and improving the patient experience" [53]. Using smartphones to deliver treatment aspects identified in the proposed model can enable several of the barriers to existing treatments to be removed. By doing so, perhaps more would seek help, in turn; reduce negative implications for the individual, for organisations and for society.

Having identified the potential of utilising smartphonebased treatments, the following section seeks to develop a framework to inform the treatment of DTDs. Formerly, findings from Sections 1 and 2 will be refined, to form DTD preconditions and criteria. Following that, methods of overcoming these will be refined, to include in the model. Then, techniques used in existing treatments will be considered, to ensure the treatment can be optimally effective by addressing barriers to recovery.

\section{A. Synthesis of Findings from Sections 1 and 2}

Sections 1 and 2 indicate that the preconditions that DTD is characterised as follows: above norm need for approval; above norm need for sensory stimulation; above norm need for social validation; above norm need for guidance and feedback; above norm need for intellectual stimulation; above norm approachavoidance attitude; above norm feelings of loneliness and anxiety; above norm reward de-sensitisation that indicates preexisting deficits of dopamine; above norm lack of perceived control in real life.

Albeit, the above is not enough to diagnose an individual with DTD, these aspects must also meet a set of criteria. These are: cases where there is not an employment link explanation; obsessive characteristics of engagement and time spent online, that are significantly above the norm; non-logical usage: including foregoing rational decisions to achieve irrational high, or losing track of time when online; incurring repugnant consequences; characteristics must be exhibited for extended periods of time, with the tendency for time and needs to increase. Methods of overcoming preconditions listed above, using DBCIs are listed in Table III.
TABLE III. ASPECTS TO INCLUDE IN THE MODEL OF TREATMENT

\begin{tabular}{|l|l|}
\hline \multicolumn{1}{|c|}{ DBCI } & \multicolumn{1}{|c|}{ Aspects to Include in Model } \\
\hline \multirow{3}{*}{ Percieved time } & $\begin{array}{l}\text { Feedback, to inform of usage and progress, such as } \\
\text { time spent on device and how time compares with } \\
\text { norms to sign-post behaviour. }\end{array}$ \\
\hline Disruptions & $\begin{array}{l}\text { Grayscale during periods of relapse and time limits } \\
\text { on usage (collaboratively decided). }\end{array}$ \\
\hline Interruptions during deviations from goals to allow \\
for self-reflection. \\
Notification tiers (collaboratively decided), \\
including restricted sounds and vibrations, to filter \\
distractions from achieving goals.
\end{tabular}

Aspects in Table III must also meet the following criteria: treatment must not be imposed, it must be desired the by individual who wishes to develop new behaviours; aspects of proposed DBCIs and aims of treatment must be detailed clearly prior to and during treatment, and agreed to by the user; data must not be shared without consent, and must be securely processed to protect the individual and any concerns identified in self-report data must be addressed.

\section{B. Existing Treatment Techniques to Enhance Model}

Since integrated approaches "tend to be successful in treating addiction and maintaining recovery" [60], the following section will explore techniques utilised within existing treatments. From which, it should be possible to extrapolate best practice to inform the proposed model. As the literature suggests that any model that seeks to change behaviour faces issues of "motivation, ambivalence and resistance", [29], specific techniques used to target these will be explored.

\section{Motivation as an Issue}

Motivation in the context of psychotherapy usually refers to avoidance motivation that occurs within the subject undergoing therapy. Avoidance motivation stems from a human desire "to evade unpleasant experiences", namely, experiential avoidance, and is thought "to protect the individual from reexperiencing past adversities" [26]. While helpful in select 
cases, an excess of avoidance motivation can contribute "'to the development and maintenance of many psychopathological disorders" [26]. Since a contributing factor to the maintenance of avoidance motivation is "mental representations of undesired transactions with the environment', methods of restructuring these will be examined [26].

\section{Methods of Targeting Avoidance Motivation}

Having identified that DTD subjects may use approachavoidance systems, approach-avoidance theories of motivation will be covered first. These "are active in the presence of potential positive or negative outcomes, respectively" [59]. To increase perceived positive outcomes, groups can be used, since they "are associated with rewards... a source of security and thought to reduce the occurrence of negative outcomes", [59].

As the proposed model seeks to shift behaviour from maladaptive use to purely productive usage, "systematic group influences on mood, information processing, perceptions, attention, and behavior" could be utilised, in the form of "group membership and interaction", which, in turn, "should impact activation of group members' approach and avoidance motivation systems" [59]. Hence, the community linkages made possible via DP within the model should allow for systematic group influences on the subjects behaviour, by increasing perceived positive outcomes.

\section{E. Ambivalence as an Issue}

Ambivalence is when individuals find it increasingly difficult to change, despite their best intentions, due to being "pulled in two directions by motivations to change and motivations to maintain the status quo" [2]. In cases where maladaptive behaviours "serve important functions", such as providing an escape from stressful day-to-day life [2], ambivalence is common.

\section{F. Methods of Overcoming Ambivalence}

A collaborative technique used in psychotherapy to overcome ambivalence is motivational interviewing (MI), which seeks to increase a "patients' own motivation for change and adherence to treatment" [66] and reduce resistance [29]. In essence, MI is "collaborative, evocative, and honouring of patient autonomy" [66], as it seeks to guide according to the subject's personal goals. By following "the acronym RULE", MI seeks to "Resist the righting reflex; Understand the patient's own motivations; Listen with empathy; and Empower the patient', [29].

MI has been found to be "equivalent to or better than other treatments such as cognitive behavioural therapy (CBT) or pharmacotherapy" when treating S-RADs, in addition to having "been shown to be efficacious" in treating several N-SRDs, such as IGD [66] and hypersexual disorder [29]. To incur maximum effect, MI requires "someone with the skill to switch among communication styles and the wisdom to seek and understand what style the patient needs" [66].

Having covered TE models on page 9, it is conceivable that the AI nurse could effectively conduct MI in the first phase of treatment. This could enable learner-centred objectives to be attained, from which, the AI nurse could measure the patient's progress via DP throughout treatment. Deviations could be actioned upon, with elements of persuasion architecture being used in relation to the subject's progress. MMQs could also be used within MI, to decipher the subject's mental models. Selfreport data throughout treatment could measure the effectiveness of treatment, by comparing initial response styles to later styles.

In addition to MI, the Principle of Effective Facilitation (PEF) could be utilised to help overcome ambivalence. The Principle of Effective Facilitation (PEF) is derived from humanistic approaches to treatment. In short, PEF entails external validation to encourage the learner to progress through stages of learning. PEF operates under the following assumption: when individuals "decide to learn', they "invest time and energy in checking the potential benefits" [67]. If the individual believes that they are positively altering their behaviour in a way that is compatible with the desired self, they will, according to humanism, seek to engage in learning.

Since individuals have a propensity to "devalue their work if not validated", the use of an "external authority" can allow for enhanced learning within PEF. By guiding the individual through various stages of learning, validating their progress, the likelihood of learning new behaviours should be increased. To incur maximum effect, the external authority should "encourage the adult learner to interact with his environment on his own terms" [67]. By identifying learner-centred objectives within MI, this should enable the AI nurse, who acts as the external authority "to facilitate self-directed learning" [67]. For example, with guidance grounded in theory and usage reports.

\section{G. Resistance as an Issue}

Resistance is the "overt or covert reluctance to change and grow" in subjects of therapeutic intervention [54]. Judgment or "adverse emotional reactions" in the therapist "unwittingly may exacerbate the client's resistance", while "gaining an accurate, empathic understanding of the client's difficulties in changing" can reduce resistance [54]. Approaches to treatment that seek to avoid resistance should feature both "active involvement in educating and stimulating the client toward greater awareness and adaptability", as well as allowing for degrees of self-directed learning [54].

\section{H. Methods of Overcoming Resistance}

To account for the above, psychoeducation could be utilised within the model. Psychoeducation involves "the provision of information, in a variety of media, about the nature of stress, posttraumatic and other symptoms, and what to do about them' [85]. In several cases, psychoeducation has been found to increase adherence to treatment and reduce relapse rates in subjects with S-RADs and N-S-RDs [65]. Having identified that DTD subjects are not always aware of the negative implications of overuse, psychoeducation could be used to fill in conceptual gaps and to provide coping mechanisms.

In the initial phase, following MI, psychoeducation could be used to educate the user of the potential outcomes of treatment and consequences of overuse. In later stages, psychoeducation could be used at times of indicated relapse, to 
reinforce the subject's motivation to participate in sustained treatment. Further, within phases of psychoeducation, mindfulness-based interventions (MBIs) could be utilised. In the past decade, MBIs have grown in popularity, due to their promising application to treating S-RADs and N-S-RDs [20].

MBIs have been found to be "successful for reducing dependence, craving, and other addiction-related symptoms by also improving mood state and emotion dysregulation" [69]. For example, by minimising "'substance misuse and craving by modulating cognitive, affective, and psychophysiological processes integral to self-regulation and reward processing", [20]. As a result, it is hypothesised that MBIs have the potential to "reverse the allostatic process by which normal reward learning is usurped by addictive substances" [20].

Though studies largely relate to S-RADs, aspects of MBIs can be integrated into the model of DTD treatment, since "MBT is an effective treatment for a variety of psychological problems, and is especially effective for reducing anxiety, depression, and stress" [37]. Having identified that DTs can produce rewards comparable to substances, utilising MBIs in the treatment could enable the subject to potentially shift dependence on online rewards to offline rewards. This is due to "the restructuring reward hypothesis", which "states that mindfulness may reduce addictive behavior by shifting the relative salience of drug and natural rewards from valuation of drug-related reward back to valuation of natural rewards that were salient before the development of addiction" [20].

Due to their ability to achieve "attention regulation and positive affect", it is conceivable that MBIs "might nonetheless increase pleasure from perceptual and sensorimotor experiences in a fashion similar to sensate-focus techniques and promote positive emotion regulation by amplifying selective attentional processes", [20].

\section{PROPOSED MODEL AND CONCLUSIONS}

For example, with "Mindfulness-Based Relapse Prevention (MBRP) and Mindfulness-Oriented Recovery Enhancement
(MORE)" that "have been tailored to directly to address the mechanisms that undergird addiction" [20]. Thus, utilising MBIs within psychoeducation could potentially enable the DTD subject to gravitate towards approach-approach as opposed to approach-avoidance.

\section{A. Response Tendency Hierarchy}

These elements should transform non-logical usage into logical, productive usage. Further, previous cases of no employment link explanation should become mostly employment link explanation. Characteristics, time and needs should return to the norm, with the overall positive effect leading to less reliance on DTs. Finally, the elements discussed and explored combine to contribute to Fig. 1 (The Tri Path model of treatment for Digital Technology Disorder).

\section{IMPLICATIONS AND AREAS FOR FUTURE RESEARCH}

The implications of this paper include health provision, treatment, corporate social responsibility, better health, wellbeing and a reduction in DTD. Thus, the authors recommend the following areas for further research: a large scale quantitative research to find the most influential path in the proposed model. Research on image kaleidoscoping regarding DTD is needed, in particular kaleidoscopic images from relevant domains of interest may provide some important answers pertaining to this vain of treatment. Furthermore agespecific research regarding DT use and disorders will address a significant research gap. Finally, utilising neuroscience to map the different phases of DTD when completing the varied phases of treatment.

Finally, the authors recognise that some people will be able to self-regulate, after/or during exposure to the DTD treatment proposed. Albeit, the authors also recognise that some people with a high propensity of addiction may need long term support from the AI nurse. Hence, further research may aim to explore time scales for different propensities of addiction.

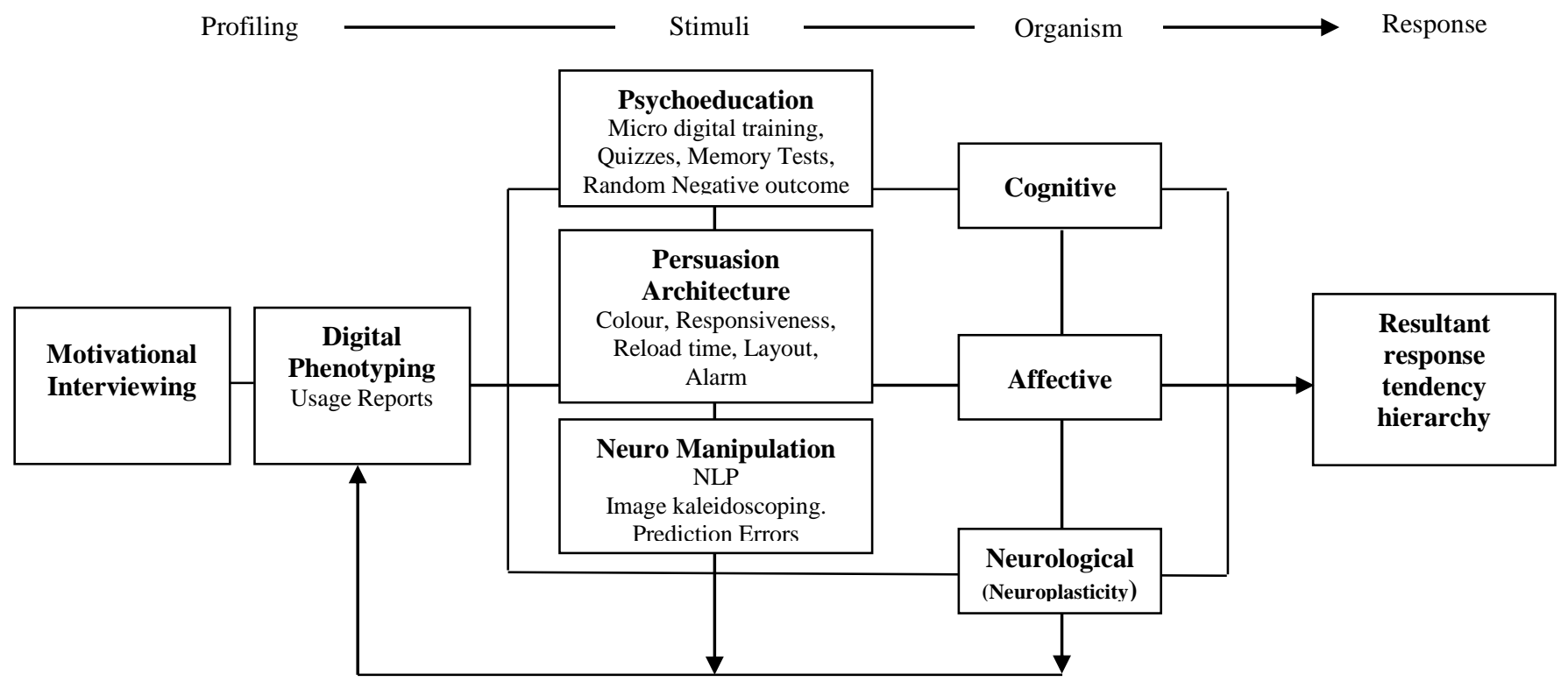

Fig. 1. Tri Path Model of Treatment for Digital Technology Disorder 


\section{REFERENCES}

[1] Allen, C., 2006. Why Machine Ethics? IEEE Intelligent Systems [online], 21 (4), 12-17.

[2] Arkowitz, H. and Lilienfeld, S., 2007. Why Don't People Change? Scientific American Mind [online], June/July 2017. Available from: http://faculty.fortlewis.edu/burke_b/counseling/cs\%20readings/sciamwhy\%20people\%20change.pdf [Accessed 6 July 2018].

[3] Becker, G. and Murphy, K., 1988. A Theory of Rational Addiction. Journal of Political Economy [online], 96 (4), 675-700.

[4] Berridge, K. and Robinson, T., 2003. Parsing reward. TRENDS in Neurosciences [online], 26 (9), 507-513.

[5] Berridge, K. Robinson, T. and Aldridge, W., 2009. Dissecting components of reward: 'liking', 'wanting', and learning. Current Opinion Pharmacology [online], 9 (1), 65-73.

[6] Bickel, W. Mueller, T. and Jarmolowicz, D., 2013. What is Addiction? In: Epstein, E. Addictions: A Comprehensive Guidebook. USA: OUP. 113.

[7] Blane H. and Kosten T., 2002. Seeking Safety: A Treatment Manual for PTSD and Substance Abuse. New York: The Guilford Press.

[8] Block, J., 2008. Issues for DSM-V: Internet Addiction. American Journal Psychiatry [online]. 165 (3), 305-306.

[9] Chalaguine, L. Hadoux, E. Hamilton, F. Hayward, A. Hunter, A. Polberg, S. and Potts, H., 2018. Domain Modelling in Computational Persuasion for Behaviour Change in Healthcare. Computer Science > Artificial Intelligence [online]. Available from: https://arxiv.org/abs/1802.10054v1 [Accessed 23 July 2018].

[10] Chassin, L. Presson, C. Rose, J. Sherman, S., 2007. What is addiction? Age-related differences in the meaning of addiction. Drug and Alcohol Dependence [online], 87 (1), 30-38.

[11] Chuttur, M., 2009. Overview of the Technology Acceptance Model: Origins, Developments and Future Directions. Sprouts: Working Papers on Information Systems [online], 9 (37), 1-21.

[12] Chwaszcz, J., 2016. Gambling and Internet addictions - epidemiology and treatment [online]. In: Chwaszcz, J. and Lelonek-Kuleta, B. Gambling and Internet addictions - epidemiology and treatment. France: Natanaelum Association Institute for Psychoprevention and Psychotherapy, 56-58.

[13] D'Alfonso, S. and Alvarez, M., 2017. 4 WAYS TECH CAN HELP YOUR MENTAL HEALTH [online]. Melbourne: Pursuit. Available from: https://pursuit.unimelb.edu.au/articles/4-ways-tech-can-help-yourmental-health [Accessed 1 May 2018].

[14] D'Arcy, J. Gupta, A. Tarafdar, M. and Turel, O., 2014. Reflecting on the "Dark Side" of Information Technology Use. Communications of the Association for Information Systems [online], 35 (5), 110-118.

[15] Davis, F., 1986. A technology acceptance model for empirically testing new end-user information systems : theory and results [online]. Thesis (PhD). Massachusetts Institute of Technology.

[16] Davis, F. Bagozzi, R. Warshaw, P., 1989. User Acceptance of Computer Technology: A Comparison of Two Theoretical Models. Management Science [online], 35 (8), 982-1003.

[17] Dillard-Wright, D., 2018. Technology Designed for Addiction [online]. United States: Psychology Today. Available from: https://www.psychologytoday.com/gb/blog/boundless/201801/technolog y-designed-addiction [Accessed 1 May 2018].

[18] Fogg, BJ., 1998. Persuasive Computers: Perspectives and Research Directions. Human-Computer Interaction [online], 225-231.[

[19] Gardner, M. Grus, J. Neumann, M. Tafjord, O. Dasigi, P. Liu, N. Peters, M. Schmitz, M. and Zettlemoyer, L., 2018. AllenNLP: A Deep Semantic Natural Language Processing Platform. arXiv [online]. Available from: https://arxiv.org/pdf/1803.07640.pdf [Accessed 19 June 2018].

[20] Garland, E. and Howard, M., 2018. Mindfulness-based treatment of addiction: current state of the field and envisioning the next wave of research. Addiction Science \& Clinical Practice [online], 13 (14), 1-14.

[21] Gonzalez, R., 2018. Can our phones save us from our phones? Wired [online], 30 January 2018. Available from: https://www.wired.com/story/can-our-phones-save-us-from-our-phones/ [Accessed 11 March 2018].
[22] Goodman, A., 1990. Addiction: definition and implications. British Journal of Addiction [online], 85 (1), 1403-1408.

[23] Grant, J. Potenza, M. Weinstein, A. and Gorelick, D., 2011. Introduction to Behavioural Addictions. The American Journal of Drug and Alcohol Abuse [online], 36 (5), 233-241.

[24] Grecu, C., 2013. THE NEW GENERATIONS AND THE ADDICTIONS TO TECHNOLOGY. European Journal of Science and Theology [online], 9 (1), 99-110.

[25] Greer, S., 2018. The Addiction Economy. Medium [online], 12 February 2018. Available from: https://medium.com/@ scottcgreer/how-do-westop-technology-addiction-c0c081b8c970 [Accessed 1 March 2018].

[26] Grosse Holtforth, M. Grawe, K. Castonguay, L., 2006. Predicting a reduction of avoidance motivation in psychotherapy: Toward the delineation of differential processes of change operating at different phases of treatment. Psychotherapy Research [online], 16 (5), 639-644.

[27] Gruber, J. and Koszegi, B., 2018. IS ADDICTION "RATIONAL"? THEORY AND EVIDENCE. The Quarterly Journal of Economics [online], 116 (1), 1261-1264.

[28] Ha, J-H. Yoo, H-J. Cho, I-H. Chin, B. Shin, D. and Kim, J-H., 2006 Psychiatric comorbidity assessed in Korean children and adolescents who screen positive for Internet addiction. Journal of Clinical Psychiatry [online], 67 (5), 821-826.

[29] Hall, K. Gibbie, T. and Lubman, G., 2012. Motivational interviewing techniques: Facilitating behaviour change in the general practice setting. Austrailian Family Physician [online], 41 (9), 660-667.

[30] Holden, C., 2001. 'Behavioral' addictions: Do they exist? Science [online], 294 (1), 980-982.

[31] Hunter, A., 2016. Computational Persuasion with Applications in Behaviour Change. Frontiers in Artificial Intelligence and Applications [online]. 287 (1), 5-18.

[32] IGI Global, 2018. What is Digital Technology [online]. Hershey: IGI Global. Available from: https://www.igiglobal.com/dictionary/digitaltechnology/7723 [Accessed 1 May 2018.

[33] Ilyas, M., 2017. Finding Relationships between Acquisition of Basic Skills and Neuro-linguistic Programming Techniques. Journal of Literature, Languages and Linguistics [online], 34 (1), 22-25.

[34] Johnson, MI. and Hudson, M., 2016. Generalizing, deleting and distorting information about the experience and communication of chronic pain. Pain Management [online], 6 (5), 411-414.

[35] Kang, Y. Tan, A-H. and Miao, C., 2015. An Adaptive Computational Model for Personalized Persuasion [online]. In: Proceedings of the Twenty-Fourth International Joint Conference on Artificial Intelligence, Argentina July 25 - 31 2015. Buenos Aires: International Joint Conference on Artificial Intelligence (IJCAI). Available from: https://dl.acm.org/citation.cfm?id=2832258 [Accessed 23 June 2018]

[36] Kemp, S., 2018. DIGITAL IN 2018: WORLD'S INTERNET USERS PASS THE 4 BILLION MARK [online]. New York: We Are Social. Available from: https://wearesocial.com/blog/2018/01/global-digitalreport-2018 [Accessed 2 May 2018].

[37] Khoury, B. Lecomte, T. Fortin, G. Masse, M. Therien, P. Bouchard, V. Chapleau, M-A. Paquin, K. Hofmann, S., 2013. Mindfulness-based therapy: A comprehensive meta-analysis. Clinical Psychology Review [online], 33 (1), 763-771.

[38] King, W. and Cleland, D., 1971. Manager-analyst teamwork in MIS: Cooperation vital in systems design. Business Horizons [online], 14 (2), 59-68.

[39] King, W. and He, J., 2006. A meta-analysis of the Technology Acceptance Model. Information \& Management [online] 43 (6), 740755.

[40] Kirsch, M., 2017. Change Your Screen to Grayscale to Combat Phone Addiction [online]. United States: Lifehacker. Available from: https://lifehacker.com/change-your-screen-to-grayscale-to-combatphone-addicti-1795821843 [Accessed 11 March 2018].

[41] Klemm, C. and Pieters, W., 2017. Game mechanics and technological mediation: an ethical perspective on the effects of MMORPG's. Ethics Information Technology [online], 19 (1), 81-93.

[42] Knorr, C., 2017. How to resist technology addiction. CNN [online], 9 November 2017. Available from: 
https://edition.cnn.com/2017/11/09/health/science-of-tech-obsessionpartner/index.html [Accessed 11 March 2018].

[43] Koob, G. and Simon, E., 2009. The Neurobiology of Addiction: Where We Have Been and Where We Are Going. J Drug Issues [online], 39 (1), 115-132.

[44] Krischkowsky, A. Maurer, B. Tscheligi, M., 2016. Captology and Technology Appropriation: Unintended Use as a Source for Designing Persuasive Technologies [online]. In: Meschtscherjakov, A. De Ruyter, B. Fuchsberger, V. Murer, M. and Tscheligi, M. Persuasive Technology. Germany: Springer, 78-83.

[45] Laurel, B., 1993. Computers as theatre. $2^{\text {nd }}$ Edition. Reading: AddisonWesley.

[46] Leeflang, P. Verhoef, P. Dahlström, P and Freundt, T., 2014. Challenges and solutions for marketing in a digital era. European Management Journal [online], 32 (1), 1-12.

[47] Ledford, H., 2009. Hidden memories guide choices. Nature [online], 9 February 2009. Available from: https://www.nature.com/news/2009/090209/full/news.2009.88.html [Accessed 19 June 2018].

[48] Leshner, A., 1999. Science is Revolutionizing Our View of Addictionand What to Do About It. The American Journal of Psychiatry [online], 156 (1), 1-3.

[49] Marsch, L. and Dallery, J., 2012. Advances in the Psychosocial Treatment of Addiction: The Role of Technology in the Delivery of Evidence-Based Psychosocial Treatment. Psychiatry Clinical North America [online], 35 (2), 481-493.

[50] Marsch, L., 2013. LEVERAGING TECHNOLOGY TO ENHANCE ADDICTION TREATMENT AND RECOVERY. Journal of Addictive Diseases [online], 31 (3), 313-318.

[51] McBain, S., 2017. How technology companies are keeping you addicted to your phone. New Statesman [online], 6 March 2017. Available from: https://www.newstatesman.com/culture/books/2017/03/how-technologycompanies-are-keeping-you-addicted-your-phone [Accessed 1 March 2018].

[52] McLeod, S., 2013. Skinner - Operant Conditioning [online]. United States: Simply Psychology. Available from: https://www.simplypsychology.org/operant-conditioning.html [Accessed 1 May 2018].

[53] Michie, S. Yardley, L. West, R. Patrick, K. and Greaves, F., 2017. Developing and Evaluating Digital Interventions to Promote Behavior Change in Health and Health Care: Recommendations Resulting From an International Workshop. Journal of Medical Internet Research [online], 19 (6), 1-11.

[54] Newman, C., 2002. A Cognitive Perspective on Resistance in Psychotherapy. Psychotherapy in Practice [online], 58 (2), 165-174.

[55] O'Brien, H. and Toms, E., 2008. What is user engagement? A conceptual framework for defining user engagement with technology. Journal of the American Society for Information Science \& Technology [online], 59 (6), 938-955.

[56] Olsen, C., 2011. Natural Rewards, Neuroplasticity, and Non-Drug Addictions. Neuropharmacology [online], 61 (7), 1109-1122.

[57] Onnela, J-P. and Rauch, S., 2016. Harnessing Smartphone-Based Digital Phenotyping to Enhance Behavioral and Mental Health. Neuropsychopharmacology [online], 41 (1), 1691-1696.

[58] Osborne, S., 2016. Chinese teen starves mother to death in revenge for sending her to abusive internet addiction boot camp [online]. London: Independent Digital News \& Media. Available from: https://www.independent.co.uk/news/world/asia/chinese-teen-starvesmother-to-death-revenge-internet-addiction-boot-camp-a7329351.html [Accessed 20 June 2018].

[59] Park, E. and Hinsz, V., 2006. "Strength and Safety in Numbers": A Theoretical Perspective on Group Influences on Approach and Avoidance Motivation. Motivation and Emotion [online], 30 (1), 135142.

[60] Patterson, E., 2015. Addiction Treatment Therapies: An Overview [online]. San Diego: Recovery Brands. Available from: https://drugabuse.com/library/addiction-treatment-therapies-anoverview/ [Accessed 1 May 2018].
[61] Pies, R., 2009. Should DSM-V Designate "Internet Addiction" a Mental Disorder? Psychiatry (Edgmont) [online], 6 (2), 31-37.

[62] Place, S. Blanch-Hartigan, D. Azarbayejani, A., 2017. Behavioral Indicators on a Mobile Sensing Platform Predict Clinically Validated Psychiatric Symptoms of Mood and Anxiety Disorders. Journal of Medical Internet Research [online], 19 (3), 1-21.

[63] Price, C., 2018. 9 Ways to Finally Stop Spending So Much Time on Your Phone. Time [online], 8 February 2018. Available from: http://time.com/5139859/smartphone-addiction-solutions/_[Accessed 2 May 2018].

[64] Psychestudy, 2018. Classical vs Operant Conditioning [online]. New York: Psychestudy. Available from: https://www.psychestudy.com/behavioral/learning-memory/classicalconditioning/classical-vs-operant [Accessed 11 March 2018].

[65] Ran, MS. Xiang, MZ. Chan, CLW. Leff, J. Simpson, P. and Huang, MS., 2003. Effectiveness of psychoeducational intervention for rural Chinese families experiencing schizophrenia: a randomised controlled trial. Social Psychiatry and Psychiatric Epidemiology [online], 38 (2), 69-75.

[66] Rollnick, S. Miller, W and Butler, C., 2008. Motivational interviewing in health care. Helping patients change behavior. New York: The Guilford Press.

[67] Rostami, K. and Khadjooi, K., 2010. The implications of Behaviorism and Humanism theories in medical education. Gastroenterology and Hepatology [online], 3 (2), 65-70.

[68] Sancho, M. De Gracia, M. Rodríguez, R. Mallorquí-Bagué, N. SánchezGonzález, J. Trujols, J. Sánchez, I. Jiménez-Murcia, S. and Menchón, J., 2018. Mindfulness-Based Interventions for the Treatment of Substance and Behavioral Addictions: A Systematic Review. Frontiers in Psychiatry [online], 9 (95), 1-9.

[69] Savardelavar, M. and Kuan, G., 2017. The use of neuro-linguistic programming as an educational-therapeutic programme: two case studies. Education in Medicine Journal [online], 9 (1), 49-58.

[70] Shapira, N-A. Lessig, M-C. Goldsmith, T-D., 2003. Problematic internet use: proposed classification and diagnostic criteria. Depression and Anxiety [online], 17 (1), 207-216.

[71] Schultz, R.L. and Slevin, D.P., 1983. The implementation profile. Interfaces [online], 13(1), 87-92.

[72] Siddique, H., 2018. UK addiction treatment centres braced for new year surge in demand. The Guardian [online], 2 January 2018. Available from: https://www.theguardian.com/society/2018/jan/02/uk-addictiontreatment-centres-braced-for-new-year-surge-in-demand [Accessed 1 May 2018].

[73] Stigler, G. and Becker, G., 1977. De Gustibus non est Disputandum. American Economic Review [online], 67 (1), 76-90.

[74] Skinner, H. and Stephens, P., 2003. Speaking the same language: the relevance of neuro-linguistic programming to effective marketing communications. Journal of Marketing Communications [online], 9 (1), 177-192.

[75] Straub, E., 2009. Understanding Technology Adoption: Theory and Future Directions for Informal Learning. Review of Educational Research [online], 79 (2), 625-649.

[76] The Interaction Design Foundation, 2018. Gamification [online]. Denmark: The Interaction Design Foundation. Available from: https://www.interactiondesign.org/literature/topics/gamification [Accessed 1 May 2018].

[77] Thomson Reuters, 2009. China bans physical punishment for Internet addicts [online]. Canada: Thomson Reuters. Available from: https://in.reuters.com/article/idINIndia-43701020091105 [Accessed 28 June 2018].

[78] Torous, J. Onnela, J-P. and Keshavan, M., 2017. New dimensions and new tools to realize the potential of RDoC: digital phenotyping via smartphones and connected devices. Translational Psychiatry [online], 7 (1), 1-3.

[79] Turel, O. Serenko, A. and Bontis, N., 2011. Family and work-related consequences of addiction to organizational pervasive technologies. Information \& Management [online]. 48 (1), 88-95. 
[80] Vaghefi, I. and Lapointe, L., 2014. When Too Much Usage Is Too Much: Exploring the Process of IT Addiction. Hawaii International Conference on System Science [online], 47 (1), 4494-4503.

[81] Venkatesh, V. and Davis, F., 2000. A Theoretical Extension of the Technology Acceptance Model: Four Longitudinal Field Studies. Management Science [online], 46 (2), 186-204.

[82] Voss, J. and Paller, K., 2009. An Electrophysiological Signature of Unconscious Recognition Memory. Nature Neuroscience [online], 12 (3), 349-355.

[83] Waelti, P. Dickinson, A. and Schultz, W., 2001. Dopamine responses comply with basic assumptions of formal learning theory. Nature [online], 412 (1), 43-48.

[84] Weinstein, A. and Lejoyeaux, M., 2010. Internet Addiction or Excessive Internet Use. The American Journal of Drug and Alcohol Abuse [online], 36 (1), 277-283.
[85] Wessely, S. Bryant, R. Greenberg, N. Earnshaw, M. Sharpley, J. and Hacker Hughes, J., 2008. Does Psychoeducation Help Prevent Post Traumatic Psychological Distress? Psychiatry [online], 71 (4), 287-301.

[86] Yau, Y. and Potenza, M., 2015. Gambling Disorder and Other Behavioral Addictions: Recognition and Treatment. Harvard Review of Psychiatry [online], 23 (2), 134-146. United States: Harvard Medical School.

[87] Yin, H. Ostlund, S. Knowlton, B. Balleine, B., 2005. The role of the dorsomedial striatum in instrumental conditioning. European Journal of Neuroscience [online], 22 (1), 513-523.

[88] Young, A., 2014. Brand Media Strategy: Integrated Communications Planning in the Digital Era. United States: Springer. 